water in the beak excite a congenital response, while the sight of water fails to do so? I believe it is because under natural conditions the chicks peck at the water in imitation of the mother, who thus shields them from the incidence of natural selection. Under these circumstances there is no opportunity for the elimination of those who fail to respond at the mere sight of water, and consequently no selective survival of those who do thus respond. But though the hen can lead her young to peck at the water, she cannot teach them the essential movements of beak, mouth, and gullet, which are necessary for the complex act of drinking. In this matter she cannot shield them from the incidence of natural selection. Those which, on pecking the water, failed to respond to the stimulus by drinking, would assuredly die of thirst and be eliminated. The rest would survive and transmit the congenital instinctive tendency. Thus it would seem that when natural selection is excluded a special mode of behaviour has not become congenitally linked with a visual stimulus; but, when natural selection is in operation, this behaviour has become so linked with a touch or taste stimulus in the beak, Similarly in the case of the pheasants and the dog. The parent birds warn the young of his approach, and thus prevent the incidence of natural selection. Hence there is no instinctive response to the sight of a terrier.

No doubt there are many cases of complex behaviour, seemingly instructive, which are difficult to explain by natural selection alone, and which have the appearance of being due to the inheritance of acquired habits. I have, however, elsewhere suggested that acquired modifications may, under the conditions of natural selection, foster the development of "coincident" variations of like nature and direction, but having their origin in the germinal substance. But into a consideration of this hypothesis I cannot here enter. Without assuming a dogmatic attitude, I am now disposed to regard the direct transmission of acquired modes of behaviour as not proven.

Thus we come back to the position, assumed at the outset, that heredity plays a double part It provides, through natural selection or otherwise, an outline sketch of relatively definite behaviour, racial in value; it provides also that necessarily. indefinite plasticity which enables an animal to acquire and to utilise experience, and thus to reach adaptation to the circumstances of its individual life. It becomes, therefore, a matter of practical inquiry to determine the proportion which the one kind of hereditary legacy bears to the other. Observation seems to show that those organisms in which the environing conditions bear the most uniform relations to a mode of life that is relatively constant, are the ones in which instinct preponderates over in. telligent accommodation; while those in which we see the most varied interaction with complex circumstances, show more adaptation of the intelligent type. And the growth of individual plasticity of behaviour, in race-development, would seem to be accompanied by a disintegration of the definiteness of instinctive response, natural selection favouring rather the plastic animal capable of indefinitely varied accommodation than the more rigid type whose adaptations are congenitally defined.

I have dealt, it will be observed, only with the lower phases and earlier manifestations of intelligence. Its higher development, and the points in which it differs from the more complex modes of human procedure, offer a wide and difficult field for careful observation and cautious interpretation. I have recently attempted further investigations in this field; but they concern rather the relation of intelligence to logical thought than that of instinct to intelligence, which forms the subject of this discourse.

\section{THE DUKE OF DEVONSHIRE ON TECHNICAL EDUCATION.}

$\mathrm{A}^{\mathrm{T}}$ Eastbourne on Saturday last the Duke of Devonshire addressed the students of the art and technical classes, and in the course of his remarks he referred to educational questions of more than local interest. His remarks upon proprietary and private schools call attention to what is probably the weakest link in our educational system. In order to qualify for an assistant mastership in an elementary school, it is necessary for a teacher to serve a term of years, during which period his knowledge of the theory and practice of teaching is periodically tested; but in our private and proprietary schools any one can be a teacher, whether he possesses qualifications or not. In other words, the elementary school teacher must prove his efficiency, while the teacher in the middle-class schools--the respectable proprietary establishments-may or may not be NO. I 475 vOL. 57] competent $t$ s impart instruction. The result is that some of our higher-grade primary schools are the best organised and equipped institutions for teaching elementary science in the country, while the science which figures in the prospectuses of many private schools is entirely unworthy of the name. Unfortunately, the sons of artisans and shopkeepers are compelled to leave school at an early age, and so cannot take full advantage of the facilities provided by the higher-grade schools. On the other hand we have the private schools where the age of leaving is later, but there the facilities for scientific instruction are inadequate. The general result is that only a small proportion, either of the artisan class or of the sons of commercial men, receive technical instruction. It is, of course, not suggested that all private schools are inefficient, but a large proportion of them are, when considered as schools in which science is taught; and the Duke of Devonshire has done a public service in pointing out the need of subjecting them to some system of supervision.

The following is abridged from the Times report of the Duke of Devonshire's address :- -

\section{Profrietary and Private Schools.}

I suppose that there are in Eastbourne a larger number of proprietary and private schools than in almost any other town of the same size in the country. It would be extremely interesting to have full information as to what these schools are doing and the nature of the instruction which they provide. I doubt very much whether there is any one here, or whether there is anybody anywhere, who has the means of forming or giving a com. plete account of what the proprietary and private schools of any particular district in the country are doing, or what is the nature of the instruction which they are providing. That appears to me to point to the need for some better organisation of education than we at present possess. Of the students who are receiving their education in the numerous proprietary schools here and in other similar schools in the country there are many, no doubt, whose future would not be dependent upon their own exertions, and who are only educating themselves, or being educated by their parents, to make them good citizens and cultivated people; but there must be a very large number in addition who are looking forward to entering into some profession or another, or into some branch of industry or of commerce. And to the parents of such students it would be of immense value and importance to have full knowledge and full information upon the character of the education which is being given at these proprietary and private schools. Some of them, no doubt, are more efficient ; some are less efficient than others; but, even amongst those which are the most efficient, there must be some which are capable of giving a more valuable hint and direction of instruction to those who are going to enter upon industrial and commercial pursuits than those which may be in other directions equally efficiently organised; and it would be of the very greatest importance, in my opinion, to the schools them. selves, to the parents, and to the community at large if means were at our disposal to know more of the manner in which these schools are organised and of the work which they are doing.

Technical Education Abroad.

Foreign nations have anticipated us to a very great extent in realising the close connection which exists between education and industrial and commercial success. That is a fact which is being brought home to us almost daily in various directions of the increasing competition to which we find ourselves in every quarter exposed. It is a subject which, as your chairman has reminded you, I have frequently discussed on previous occasions, and $I$ am not going to enter into it at any length again to-night. I will only say that the urgency of this question is now recognised by those who are educational experts or educational enthusiasts. The urgency of the question is coming to be recognised by practical men of business. Only the other day the education authority of Manchester sent out a deputation of its members to ascertain what provision was being made in Germany and Switzerland for the industrial and commercial education of the people. They published a most valuable report, in which they spoke almost with dismay of the completeness with which the education of those who were leading and directing the manufacturing and commercial enterprise of those countries was being organised; and they urged upon their fellow-citizens, in the very strongest terms, that they should not allow themselves to be left behind in the race, but that they should make an effort for the organisation of the education of 
their own people to bring that education up to something like the level which has been attained in those countries. And the Associated Chambers of Commerce the other day presented a memorial, a most important memorial, to the Government urging upon them that greater attention should be paid by the educational departments of the State, not to art and scientific instruction only, but to the study of foreign languages and other subjects indispensable to the successful prosecution of a com. mercial career. And therefore I say it is not educational enthusiasts only, but it is practical and far-headed men of business who are beginning to realise the absolute necessity of bringing up our education somewhere near, at all events, to the levels which have been attained in other countries.

\section{Organisation of Secondary Education.}

I have not the smallest desire to see our secondary education modelled upon one uniform pattern. I believe that we require great variety and great freedom, but I do think that it would be of advantage if both central and local organisations existed with which these private institutions might place themselves in voluntary, but, at the same time, in close connection-organisations which, by means, perhaps, of inspection, by their guidance, and by their counsel-might enable them so to organise themselves, so to co-relate themselves, as to render the instruction which they may give more valuable to the public. These are, of course, observations of a very general character, which, if they have any substance, apply equally to schools in every part of the country. Speaking of this particular district-of your own schools-I cannot help thinking that it might be of great advantage, both to them and to the community of Eastbourne, if, under the county educational authority or under your borough educational authority - there ought not to be any jealousy between different bodies of that kind--there could be established in this town of Eastbourne a scientific and technical institute, which might be of great value to the inhabitants of Eastbourne itself and also of great assistance to those educational establishments which are so numerous amongst you, and which might make use of such establishments as part of their educational course.

\section{PRILE SUBJECTS OF THE PARIS ACADEMY OF SCIENCES.}

THE Comples rendus of the Paris Academy of Sciences, for January Io, contains the list of subjects proposed for the various prizes offered by the Academy for 1898 and three succeeding years.

For the year 1898, the subject for the Grand Prize of the Mathematical Sciences is to examine and extend the part played by divergent series in analysis; for the Bordin Prize (3000 fr.), to study the questions relating to the determination, properties, and applications of systems of orthogonal curvilinear coordinates of $n$ variables, indicating especially the degree of generality of these systems; the Francœur Prize (IOOO fr.) and Poncelet Prize (2000 fr.), for the most useful work in the field of pure or applied mathematics. In Mechanics, the Extraordinary Prize of $6000 \mathrm{fr}$., for progress in any direction calculated to increase the efficiency of the French naval forces; the Montyon Prize (700 fr.), for inventing or improving instruments useful to the progress of agriculture, the mechanical arts or sciences; the Plumey Prize ( $2500 \mathrm{fr}$.), for improvements in steam engines, or any other invention contributing to the progress of steam navigation; the Fourneyron Prize (500 fr.), for the theory of the motion of bicycles, discussing more especially the conditions of stability of both rectilinear and curved motion on a horizontal or inclined plane.

In Astronomy, the Lalande Prize ( $540 \mathrm{fr}$.), for the most interesting observation, or the work or memoir most useful to the progress of astronomy; the Damoiseau Prize ( $1500 \mathrm{fr}$.), for an exposition of the theory of the perturbations of Hyperion, the satellite of Saturn, taking account principally of the action of Titan, comparing the observations with the theory, and hence deducing the mass of Titan; the Valz Prize ( $460 \mathrm{fr}$.), for the most interesting astronomical observation made during the current year; the Janssen Prize (a gold medal), for discoveries in physical astronomy.

In Statistics, the Montyon Prize (500 fr.), for questions relating to French statistics; and in Chemistry, the Jecker Prize (Io,000 fr. ), for work in organic chemistry.

In Mineralogy and Geology, the Vaillant Prize (4000 fr.), for a work discussing and making known the indications furnished by the microscopical study of sedimentary rocks (particularly secondary and tertiary) from the point of view of their genesis and of the modifications which they have undergone since their deposit in structure and composition, organised bodies being included.

In Botany, the Barbier Prize (2000 fr.), for discoveries bearing upon the art of healing; the Desmazières Prize ( $1600 \mathrm{fr}$.), for the best study of Cryptogams; the Montagne Prizes ( $1000 \mathrm{fr}$. and $500 \mathrm{fr}$.), for memoirs bearing on the anatomy, physiolngy, and development of the lower Cryptogams; the De la FonsMelicocq (900 fr.), for botanical work on the North of France ; and the Thore Prize (200 fr.) to the author of the best work on the cellular Cryptogams of Europe.

In Anatomy and Zoology, the Savigny Prize (97.5 fr.), for the assistance of young travelling zoologists, not receiving Governmental support, who have specially occupied themselves with the invertebrate fauna of Egypt and Syria.

In Medicine and Surgery, a Montyon Prize for discoveries or inventions bearing on medicine or surgery; the Barbier Prize (2000 fr.), for the most valuable discovery in relation to the art of healing (surgery, medicine, pharmacy or botany); the Bréant Prize (100,000 fr.), for a discovery leading to the complete suppression of Asiatic cholera ; the Godard Prize ( 1000 fr.), for the best memoir on the anatomy, physiology, and pathology of the genito-urinary organs; also the Bellion (I 400 fr.); Mège Lallemand (1800 fr.), and Baron Larrey Prizes.

In Physiology, a Montyon Prize (750 fr.); the Pourat Prize (I $400 \mathrm{fr}$.), for a memoir on the motor nerves of the stomach, and the Philipeaux Prize ( 890 fr.).

In Physical Geography, the Gay Prize (2500 fr.), for a comparison between the marine flora of the Bay of Biscay with that of neighbouring regions and of the Mediterranean; also to see if the fauna and flora lead to similar conclusions. Other general prizes offered are the Arago Medal, the Montyon Prize (unhealthy trades), the Trémont Prize (I 100 fr.), the Gegner Prize (4000 fr.), the Delalande-Guérineau Prize (I000 fr.), the Jérome Ponti Prize (3500 fr.), the Leconte Prize (50,000 fr.), for a new and important discovery in mathematics, physics, chemistry, natural history, or medical science; the Tchiatcheff Prize (3000 fr.), for exploration of the lesser-known portions of Asia the Houllevigue Prize, the Cahours Prize (3000 fr.), for the assistance of young chemists of promise; the Saintour Prize (3000 fr.), the Kastner-Boursault Prize (2000 fr.), for the best work on the applications of electricity in the arts, industry, and commerce; and the Estrade-Delcros Prize ( $8000 \mathrm{fr}$.).

Of these prizes, those of Montagne and Delalande-Guèrineau are expressly restricted to Frenchmen, whilst the Lalande, La Caze, Delesse, Desmazières, Tchiatcheff, and Leconte Prizes are awarded without distinction of nationality.

\section{MR. CAVENDISH ON HIS JOURNEY TO LAKE RUDOLF.}

N Monday last, Mr. H. S. H. Cavendish described his recent journey in East Africa before the Koyal Geographical Society. Accompanied by Lieut. H. Andrew, Mr. Cavendish left Berbera on September 5, 1896, and proceeded in a southerly direction to Lugh, on the Juba River, afterwards striking westwards up the Dau. Here it proved very difficult to get into communication with the natives, as the caravan was at first taken for an Abyssinian force. The country of the Boran Gallas, with whom Dr. Donaldson Smith had so much trouble, was, however, soon reached. Mr. Cavendish gave some interesting details respecting this tribe, which he found most friendly, and anxious to be placed under British protection. Whilst in the Boran country the travellers were able to wander about at will without escort. At Egder, in about lat. $4^{\circ} \mathrm{N}$., long. $39^{\circ}$ E., Dr. Donaldson Smith's route was left, and the caravan made direct for Lake Stefanie, passing a remarkable crater with a lake at the bottom, from which salt is obtained. At the south end of Lake Stefanie a large outcrop of coal was discovered, which had evidently been laid bare by the action of the water. It was in this neighbourhood that Mr. Cavendish had an adventure with an elephant which well-nigh proved fatal. Some valuable information was collected with regard to the tribes on the western side of the lake, the principal of which are the Wanderobo (allied to the Borans), the Harbora, Hamerkoke (nomads), and Galubba. Striking across to the north end of Lake Rudolf, the travellers reached the country of the Reshiat or Darsonich, a race of traders, but, like other tribes of the

NO. 1475 , vOL. 57] 